\title{
(2) OPEN ACCESS \\ Effect of Instrumental Activities of Daily Living habituation due to routinising therapy in patients with frontotemporal dementia
}

\author{
Kosuke Nakanishi, Takayoshi Yamaga
}

Occupational Therapy, Health Science University, Minamitsurugun, Japan

\section{Correspondence to}

Professor Kosuke Nakanishi; knakanishi@kenkoudai.ac.jp

Accepted 14 January 2021

Check for updates

(c) BMJ Publishing Group Limited 2021. Re-use permitted under CC BY-NC. No commercial re-use. See rights and permissions. Published by BMJ.

To cite: Nakanishi K Yamaga T. BMJ Case

Rep 2021;14:e240167.

doi:10.1136/bcr-2020

240167

\section{SUMMARY}

We examined whether Instrumental Activities of Daily Living (IADL) improves with routinising therapy for a patient with frontotemporal dementia (FTD) living in a group home. The patient exhibited symptoms of agitation, apathy, disinhibition, irritability and stereotyped behaviour. The care staff experienced longterm care burden and the patient was spending time idly. An occupational therapist, in collaboration with care staff, evaluated the patient and routinised the household chores included in IADL. Consequently, a routine of household chores was established, reducing behavioural and psychological symptoms of dementia and long-term care burden, and the quality of life (QOL) of the patient improved. The results suggested that routinising IADL of the patient with FTD reduced long-term care burden and improved QOL of the patient.

\section{BACKGROUND}

Frontotemporal dementia (FTD) is a clinical syndrome characterised by progressive deterioration of personality, social relationships and cognition. ${ }^{1}$ However, using relatively preserved episodic memory and procedural memory is an important strategy in providing care. ${ }^{2} 3$ Patients with early-stage FTD clinically experience the potential ability to perform Instrumental Activities of Daily Living (IADL), but effective rehabilitation interventions remain unclear. Previous studies have reported a few routinising therapies that use stereotyped behaviour associated with FTD to immerse patients in activities of interest, such as hobbies and preferences. Tanabe et al ${ }^{4}$ reported that routinising the work that the patient was interested in reduced his/her troubles with others and the long-term care burden of caregivers. Lough and Hodges ${ }^{5}$ reported that routinising simple work was effective in improving behavioural and psychological symptoms of dementia (BPSD). However, after these reports were published, almost no research on routinising therapy in patients with FTD has been reported in recent years. Moreover, it is unclear whether IADL, which involves complex processes, can be adapted to routinising therapy for patients with FTD.

We present a case study where intervention for routinising IADL was introduced in a patient with FTD, who had never performed any IADL at all while living in a group home. ${ }^{6}$ It is expected that routinising therapy is effective in improving IADL in patients with FTD.

\section{CASE PRESENTATION}

The patient was a 69-year-old woman. She gave birth to a child at the age of 25 years and was a (full-time) homemaker until she got divorced at the age of 34. She started living alone at the age of 43 after her child entered university. After working for 20 years at a supermarket, the woman retired at the age of 54. Thereafter, she increasingly spent time alone at home during the day. After a few years, she started repeating acts such as trying to take items from convenience stores without paying (shoplifting), and making loud noises when entering or leaving her house, such as knocking or slamming the door, which led to complaints from nearby stores and neighbours. Accordingly, at the age of 57 , she underwent psychiatric examination and was diagnosed with FTD. After this diagnosis, she was placed in a group home. The patient has lived in the group home ever since.

The subject did not have any physical function impairment that would inhibit the activities of daily life. In the group home, she used to perform minimum self-care, such as cleaning her room by herself. However, in the group home, she rarely performed the household chores that she used to undertake while living in her house. Previously, she had at times engaged in making seasonal ornaments with the care staff, but she did not continue such activities for long. When in a bad mood, she had altercations with other residents and care staff, and even locked herself in her room at times. There were instances where watching other residents participating in activities with care staff, in which she was not participating, resulted in a bad mood out of jealousy. She used to be angry if she was not the first one allowed to take a bath. The patient would spend most of her time doing nothing, sitting at the same table and in the same chair in the living room, and used to take meals at the same place every day. The burden on the care staff was high since the patient created a commotion if some other resident occupied her usual place.

\section{INVESTIGATIONS}

The patient was assessed before the intervention and 2 weeks after the intervention administered by the occupational therapist. The scores shown in tables 1 and 2 were recorded using the following assessment tools: 
Table 1 Improvement of activities of daily living (HADLS) score after the intervention of the IADL

\begin{tabular}{lcc}
\hline Activities & Before & After \\
\hline Toileting & 0.5 & 0.5 \\
\hline Eating & 0 & 0 \\
\hline Dressing & 2.8 & 2.8 \\
\hline Grooming & 1.3 & 1.3 \\
\hline Face washing & 2.1 & 2.1 \\
\hline Brushing & 0 & 0 \\
\hline Teeth and bathing & 3.1 & 3.1 \\
\hline Going out & 4.7 & 4.7 \\
\hline Telephoning & 4 & 4 \\
\hline Shopping & 3.9 & 3.9 \\
\hline Making meals & 3.7 & 3.7 \\
\hline Cleaning rooms & 2.4 & 2.4 \\
\hline Making beds & 2.5 & 2.5 \\
\hline Washing dishes & 2.7 & 0.7 \\
\hline Laundering & 2.5 & 2.5 \\
\hline Managing fire & 4.9 & 4.9 \\
\hline Using electric light and television switches & 1.5 & 1.5 \\
\hline Paying bills & 4.2 & 4.2 \\
\hline Total (100) & 46.8 & 44.8 \\
\hline
\end{tabular}

HADLS, Hyogo Activities of Daily Living Scale; IADL, Instrumental Activities of Daily Living.

- Hyogo Activities of Daily Living Scale (HADLS).

- Neuropsychiatric Inventory-Nursing Home Version (NPI-NH). ${ }^{8}$

- Quality of Life in Alzheimer's Disease (QOL-AD). ${ }^{9}$

- Mini-Mental State Examination (MMSE). ${ }^{10}$

- Clinical Dementia Rating (CDR). ${ }^{11}$

HADLS is a comprehensive impairment scale for daily life activities in patients with dementia. NPI-NH is a facility version tool for assessing BPSD, and a version in Japanese is also available. ${ }^{12} \mathrm{QOL}-\mathrm{AD}$ is a QOL scale specifically designed for patients with dementia, for which a version in Japanese is also available. ${ }^{13}$ All these assessment scales have been confirmed to be reliable and valid.

The patient's total HADLS score for activities of daily living was 46.8 , with a score of 2.7 for subitem 'clean-up after meals', which she seldom undertook. The occupational therapist clinically judged that the clean-up after meals can be performed if done together with the care staff. The total NPI-NH score

Table 2 Improvement of BPSD and burden (NPI-NH), QOL (QOL$A D)$, cognitive function (MMSE), staging of dementia (CDR) score after the intervention of the IADL

\begin{tabular}{lcc}
\hline & Before & After \\
\hline NPI-NH & & \\
\hline Agitation & 4 & 3 \\
Apathy & 3 & 1 \\
\hline Disinhibition & 3 & 2 \\
Irritability & 4 & 2 \\
\hline Burden & 7 & 4 \\
QOL-AD & 39 & 44 \\
MMSE & 18 & 18 \\
CDR & 2 & 2 \\
\hline
\end{tabular}

CDR, Clinical Dementia Rating; IADL, Instrumental Activities of Daily Living; MMSE, MiniMental State Examination; NPI-NH, Neuropsychiatric Inventory-Nursing Home Version; QOL-AD, Quality of Life in Alzheimer's Disease. for BPSD was 14, with subitem scores of 4 for agitation, 3 for apathy, 3 for disinhibition and 4 for irritability. The level of longterm care burden due to BPSD was assessed as 7 given by the long-term care burden item in NPI-NH. The QOL scores using QOL-AD was 39. Cognitive function score assessed using MMSE was 18 . The degree of severity of dementia assessed using CDR was 2 (tables 1 and 2).

\section{DIFFERENTIAL DIAGNOSIS}

In the guidelines for the treatment of dementia 2017 supervised by the Japanese Society of Neurology, FTD is used as a clinical diagnostic name that encompasses behavioural variant frontotemporal dementia (bvFTD), semantic dementia and progressive non-fluent aphasia. ${ }^{14}$ The subject met the diagnostic criteria for bvFTD, that is, the clinical picture with progressive and persistent symptoms including early behavioural disinhibition, early apathy, early loss of empathy and early stereotyped behaviour that meet international consensus criteria for bvFTD by the International Behavioural Variant FTD Criteria Consortium. ${ }^{1}$ However, due to the patient's financial constraints and barriers to a definitive diagnosis, no formal cognitive screening, diagnostic imaging or pathological examination was performed to examine the diagnosis or stage of disease in detail. As a result, the subject was also diagnosed with FTD since the Japanese guidelines use FTD as a clinical diagnosis that encompasses all three types.

\section{TREATMENT}

Routinising therapy refers to the method in which the patient is guided to perform activities that the patient is interested in or prefers, by using the easily preserved episodic memory, procedural memory and visuospatial cognitive functions of patients with FTD. ${ }^{2-5} 14$ Such activities are then incorporated into the daily routine by appropriately using the stereotyped behaviour in a positive sense. Using HADLS, the occupational therapist, together with the care staff, extracted the IADL that the patient was undertaking in daily activities at her residence but not doing currently at the group home. The occupational therapist selected the IADL of 'clean-up after meals' assuming that the patient would likely be able to complete the task if it was done together with care staff. Next, a positive response was obtained when the patient was asked whether she would like to try 'clean-up after meals'. In line with the patient's wish, it was decided that the IADL of 'clean-up after meals' would be the task undertaken in the routinising therapy. The occupational therapist instructed the care staff to guide the patient in performing the clean-up after meals more than once per day. Moreover, the care staff was also instructed to say words of appreciation and gratitude every time the patient completed the clean-up after meals. The intervention period was set as 2 weeks, hypothesising that even in a short time routinising the IADL would lead to an improvement in IADL capability.

The care staff guided the patient in performing the household chores every day for 2 weeks, and the patient was able to complete the household chores together with the care staff. On day 1 and day 2, responding to the guidance by the care staff with a smiling face and in good mood, the patient performed the clean-up after meals. On day 3, the patient on her own volition performed the activity of 'wiping the table' when she noticed the wiping cloth placed on the table. On day 4 and afterwards, she was able to wash the dishes even more carefully. On day 6 and afterwards, she started looking forward to clean-up after meals as soon as she had finished eating. On day 7 and afterwards, 
she wanted to wear an apron while performing the household chores. On day 8 and afterwards, the instances in which she conversed the care staff with a smile while performing clean-up after meals also increased.

\section{OUTCOME AND FOLLOW-UP}

After the intervention, the total HADLS score was 44.8, with a score of 0.7 for the subitem 'clean up after meals'. The total NPI-NH score was 4 , with subitem scores of 3 for agitation, 1 for apathy, 2 for disinhibition and 2 for irritability. The QOL-AD score was 44 . The MMSE score was 18 . The CDR score was 2 (tables 1 and 2).

In the follow-up over 1 month after the 2-week intervention, the routine of clean-up after meals was found to be established. Moreover, the patient started to amicably converse even with the residents whom she had previously disliked. Additionally, instances of locking herself up in her room became fewer, and instances of altercations with other residents ceased almost completely.

\section{DISCUSSION}

In this case study, we referred to the current ADL status and daily living history of the patient having more than three clinical features in formulating the routinising therapy to adapt the stereotyped behaviour to IADL. Moreover, a new finding for us was that focusing on IADL in the intervention enabled the patient to perform it in a short time, improving the IADL capability. Additionally, another point worthy of attention was that the BPSD decreased as the IADL capability improved.

In the Japanese guidelines, non-drug therapies such as care and behaviour therapy considering FTLD symptomatology are recommended as $2 \mathrm{C}$ ('weak recommendation, weak rationale' based on the combination of recommended grade and evidence level) category. ${ }^{14}$

Disinhibition, stereotyped behaviour and decreased spontaneity are observed as the early-stage symptoms of FTD. However, memory impairment and visuospatial impairment are not noticeable in the early stage. ${ }^{415}$ In this case, as the intervention continued, the patient increasingly looked forward to performing the IADL. The point worthy of attention here is that it indicates that for a patient with FTD, it is easier to preserve prospective memory for remembering what to do from now on. In summary, patients with FTD exhibit less memory (functional) impairment compared with patients with Alzheimer dementia and other types of dementia, and this can be considered important in formulating the therapy strategy for treating behaviour impairment associated with FTD. ${ }^{4}$

The long-term care burden of caregivers due to BPSD in patients with FTD has been reported as an issue. ${ }^{16-19}$ In care facilities also, it is necessary to reduce the long-term care burden. It has been reported that introducing routinising therapy inwards has reduced the long-term care burden. ${ }^{4}$ In this case, routinising therapy was administered guaranteeing patient-centred care, by obtaining consent before the IADL intervention that the patient wants to do household chores. Consequently, troubles with others and BPSD such as agitation, apathy, disinhibition and irritability were reduced, resulting in a reduction in long-term care burden. In a systematic review of clinical experiments on non-drug therapies, Shinagawa $e t \mathrm{al}^{20}$ mentioned that based on a study with six patients with FTLD, Ikeda et al from Japan have reported that care using memory function and visuospatial function was effective, leading to sustaining QOL. Merrilees $e t \mathrm{al}^{21}$ reported that there were cases where it was possible to decrease abnormal behaviour and reduce the burden on caregivers, by using the (remaining) preserved functions and past lifestyle of the patient. In this case, also, using the patient's stereotyped behaviour to adapt to IADL in the routinising therapy improved the QOL of the patient and reduced the long-term care burden of the care staff. These findings corroborate the observations in previous reports.

In this case report, since the investigation was limited to the comparison of before and after the intervention for only one case (patient), it cannot be said that the results apply to every patient with FTD. However, it is especially worth mentioning that incorporating IADL in the activities in routinising therapy improves IADL capability and QOL of the patient, which leads to reducing BPSD and long-term care burden. Incorporating such measures in care for patients with FTD can be considered effective hereafter.

\section{Patient's perspective}

The patient said, "I look forward to cleaning up after meals every day. Up until now, no one expected me to clean up after meals or let me do it. I was made to spend my time just sitting in the living room. But I feel a little bit happier now."

Her care staff said, "She's started to clean up after her meals and she's happier and smiles more every day. And most importantly, she is less angry and verbally abusive. It has made it easier for us to care for her."

\section{Learning points}

Sustaining and improving Instrumental Activities of Daily Living (IADL) using the residual (preserved) functions such as memory function in patients with frontotemporal dementia (FTD) is an important strategy in providing care.

- Adapting IADL of patients with FTD living in group home to routinising therapy is an effective measure.

- Using routinising therapy likely improves IADL and quality of life, and consequently, behavioural and psychological symptoms of dementia and associated long-term care burden also reduce.

Contributors $\mathrm{KN}$ contributed to the acquisition of data, the conception, design, drafting the manuscript, final approval of the version sent for publication and has agreed to be accountable for the article. TY contributed to drafting the manuscript, analysis and interpretation of data, revising it critically for intellectual content and agreed to be accountable for the article.

Funding The authors have not declared a specific grant for this research from any funding agency in the public, commercial or not-for-profit sectors.

\section{Competing interests None declared.}

Patient consent for publication Next of kin consent obtained.

Provenance and peer review Not commissioned; externally peer reviewed.

Open access This is an open access article distributed in accordance with the Creative Commons Attribution Non Commercial (CC BY-NC 4.0) license, which permits others to distribute, remix, adapt, build upon this work non-commercially, and license their derivative works on different terms, provided the original work is properly cited and the use is non-commercial. See: http://creativecommons.org/ licenses/by-nc/4.0/.

\section{REFERENCES}

1 Rascovsky K, Hodges JR, Knopman D, et al. Sensitivity of revised diagnostic criteria for the behavioural variant of frontotemporal dementia. Brain 2011;134:2456-77.

2 Ritchie CW. Therapeutic strategies in dementia. Clinical Pub: Oxford; Ashland, $\mathrm{OH}$, 2007. 
3 Ikeda M, Tanabe H, Horino T, et al. [Care for patients with Pick's disease--by using their preserved procedural memory]. Seishin Shinkeigaku Zasshi 1995;97:179-92.

4 Tanabe H, Ikeda M, Komori K. Behavioral symptomatology and care of patients with frontotemporal lobe degeneration - based on the aspects of the phylogenetic and ontogenetic processes. Dement Geriatr Cogn Disord 1999;10:50-4.

5 Lough S, Hodges JR. Measuring and modifying abnormal social cognition in frontal variant frontotemporal dementia. J Psychosom Res 2002;53:639-46.

6 Yokota O, Fujisawa Y, Takahashi J, et al. Effects of group-home care on behavioral symptoms, quality of life, and psychotropic drug use in patients with frontotemporal dementia. J Am Med Dir Assoc 2006;7:335-7.

7 Hirono N. A novel scoring system of activities of daily living for patients with Alzheimer's disease. Hyogo Activities of Daily Living Scale (HADLS). Jpn J Neuropsychol 1997;13:260-9.

8 Wood S, Cummings JL, Hsu MA, et al. The use of the neuropsychiatric inventory in nursing home residents. Characterization and measurement. Am J Geriatr Psychiatry 2000;8:75-83

9 Logsdon RG, Gibbons LE, McCurry SM. Quality of life in Alzheimer's disease: Patient and caregiver reports. Journal of Mental Health and Aging 1999;5:21-32.

10 Folstein MF, Folstein SE, McHugh PR. "Mini-mental state". A practical method for grading the cognitive state of patients for the clinician. J Psychiatr Res 1975;12:189-98.

11 Hughes CP, Berg L, Danziger WL, et al. A new clinical scale for the staging of dementia. Br J Psychiatry 1982;140:566-72.

12 Shigenobu K, Hirono N, Tabushi K, et al. [Validity and reliability of the Japanese Version of the Neuropsychiatric Inventory-Nursing Home Version (NPI-NH)]. Brain Nerve 2008;60:1463-9.
13 Matsui T, Nakaaki S, Murata Y, et al. Determinants of the quality of life in Alzheimer's disease patients as assessed by the Japanese version of the quality of Life-Alzheimer's disease scale. Dement Geriatr Cogn Disord 2006;21:182-91.

14 Japanese Society of Neurology ed. Guidelines for the treatment of dementia 2017. IGAKU-SHOIN Ltd, 2017.

15 Bozeat S, Gregory CA, Ralph MA, et al. Which neuropsychiatric and behavioural features distinguish frontal and temporal variants of frontotemporal dementia from Alzheimer's disease? J Neurol Neurosurg Psychiatry 2000;69:178-86.

16 Boutoleau-Bretonnière C, Vercelletto M, Volteau C, et al. Zarit burden inventory and activities of daily living in the behavioral variant of frontotemporal dementia. Dement Geriatr Cogn Disord 2008;25:272-7.

17 de Vugt ME, Riedijk SR, Aalten P, et al. Impact of behavioural problems on spousal caregivers: a comparison between Alzheimer's disease and frontotemporal dementia. Dement Geriatr Cogn Disord 2006;22:35-41.

18 Riedijk SR, De Vugt ME, Duivenvoorden HJ, et al. Caregiver burden, health-related quality of life and coping in dementia caregivers: a comparison of frontotemporal dementia and Alzheimer's disease. Dement Geriatr Cogn Disord 2006;22:405-12.

19 Snowden JS, Neary D, Mann DMA. Fronto-temporal lobar degeneration : frontotemporal dementia, progressive aphasia, semantic dementia. New York: Churchill Livingstone, 1996.

20 Shinagawa S, Nakajima S, Plitman E, et al. Non-Pharmacological management for patients with frontotemporal dementia: a systematic review. J Alzheimers Dis 2015:45:283-93.

21 Merrilees J. A model for management of behavioral symptoms in frontotemporal lobar degeneration. Alzheimer Dis Assoc Disord 2007;21:S64-9.

Copyright 2021 BMJ Publishing Group. All rights reserved. For permission to reuse any of this content visit https://www.bmj.com/company/products-services/rights-and-licensing/permissions/

BMJ Case Report Fellows may re-use this article for personal use and teaching without any further permission.

Become a Fellow of BMJ Case Reports today and you can:

- Submit as many cases as you like

- Enjoy fast sympathetic peer review and rapid publication of accepted articles

- Access all the published articles

Re-use any of the published material for personal use and teaching without further permission

Customer Service

If you have any further queries about your subscription, please contact our customer services team on +44 (0) 2071111105 or via email at support@bmj.com.

Visit casereports.bmj.com for more articles like this and to become a Fellow 